
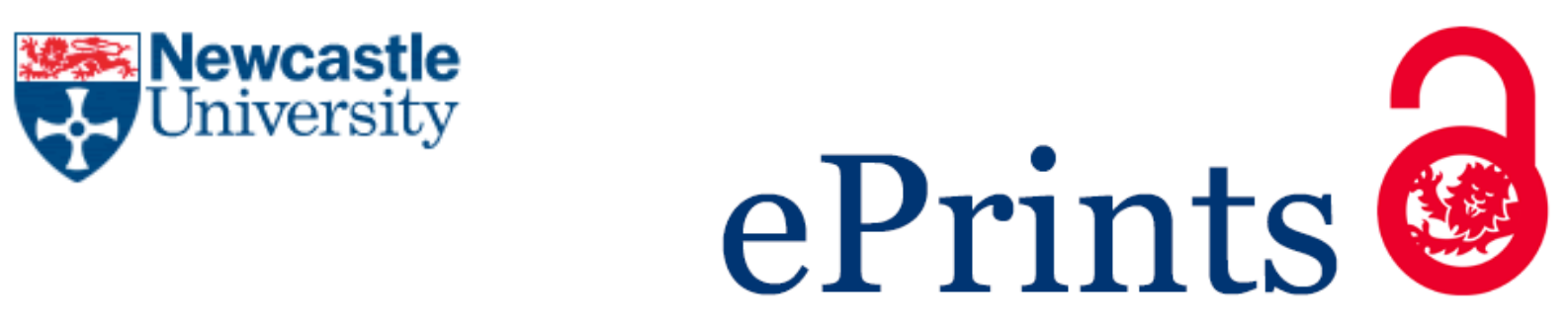

Spyridopoulos I, Arthur HM.

Microvessels of the Heart: formation, regeneration and dysfunction.

Microcirculation 2016

DOI: http://dx.doi.org/10.1111/micc.12338

\title{
Copyright:
}

This is the peer reviewed version of the following article: Spyridopoulos I, Arthur HM. Microvessels of the Heart: formation, regeneration and dysfunction. Microcirculation 2016, which has been published in final form at http://dx.doi.org/10.1111/micc.12338. This article may be used for non-commercial purposes in accordance with Wiley Terms and Conditions for Self-Archiving.

DOI link to article:

http://dx.doi.org/10.1111/micc.12338

Date deposited:

19/01/2017

Embargo release date:

07 December 2017 
Received Date : 30-Nov-2016

Revised Date : 01-Dec-2016

Accepted Date : 02-Dec-2016

Article type : Invited Reviews

\section{Microvessels of the Heart: formation, regeneration and dysfunction}

loakim Spyridopoulos ${ }^{1}$

Helen M Arthur ${ }^{1}$

${ }^{1}$ Institute of Genetic Medicine, Centre for Life, Newcastle University, Newcastle, NE1 3BZ,

U.K.

Corresponding author mail id: helen.arthur@ncl.ac.uk

Running Title: Microvessels of the Heart

Corresponding Author

Helen M Arthur, Institute of Genetic Medicine, Centre for Life, Newcastle University, Newcastle, NE1 3BZ, U.K.

\section{Abstract}

This issue of Microcirculation focusses on the special topic of "microvessels of the heart" and contains five state-of-the-art reviews and one expert article that reflect current efforts to address the major gaps in our understanding of these key microvessels. In the adult heart, most attention until recently (especially among the clinical cardiology community) has been given to the main coronary arteries, which are the culprit vessels in patients with coronary

This article has been accepted for publication and undergone full peer review but has not been through the copyediting, typesetting, pagination and proofreading process, which may lead to differences between this version and the Version of Record. Please cite this article as doi: 10.1111/micc.12338

This article is protected by copyright. All rights reserved. 
artery disease, including its most serious manifestation, acute myocardial infarction (MI). However, due to major advances in efficiently reopening the acutely blocked coronary arteries, $\mathrm{Ml}$ is no longer the killer disease it once was. In contrast, there are few treatment options for patients who develop microvascular obstruction during acute MI. Indeed, we have a very poor understanding of this disease, or even how heart vessels are initially formed in development. This is surprising in light of the essential nature of the cardiac microvessels for efficient cardiac function throughout life. The articles in this issue are from six keynote speakers at the 66th annual meeting of the British Microcirculation Society at Newcastle University and review our understanding of these key vessels from initial development to their role in adult heart disease.

Keywords Microvascular obstruction, microRNA, angiogenesis, MSCs, STEMI

This special issue of Microcirculation contains 5 state-of-the-art reviews and one primary paper by invited keynote speakers who participated in the $66^{\text {th }}$ annual meeting of the British Microcirculation Society (BMS) at Newcastle University on $7^{\text {th }}$ and $8^{\text {th }}$ April 2016. This was the society's first return "home" since the BMS was founded in Newcastle in 1963. Importantly basic scientists and clinicians joined forces in this meeting to consider the role of the cardiac microvasculature in maintaining a healthy heart, how these vessels develop and how they are regenerated in disease. The overarching goal of the meeting was to drive a better understanding of these essential microvessels in order to address the challenging problems caused by cardiac microvascular disease in patients.

Major recent advances in our knowledge of how the cardiac vasculature forms during development are reviewed in this issue by Nicola Smart [10]. Understanding the mechanisms that underpin development of the cardiac vessels is not only important to improve our knowledge of how these key vessels form in the embryo, but also because many of the cellular and molecular changes that occur during initial vascularisation of the 
heart are recapitulated in regeneration and repair of the adult heart following injury. Increased understanding of these processes will inform improved strategies to promote revascularisation of the ischaemic heart or, in cardiac regeneration, to vascularise transplanted myocardial cells or tissues. Insights gained from studying the embryo may also reveal novel pathways that can be activated pharmaceutically to promote neo-vessel formation in the ischaemic adult heart. There has been a recent surge of studies using mouse genetics to track the cellular origins of the coronary vessels, spiced by a measure of controversy in the field. Sometimes the expression patterns of the Cre recombinases used for these experiments has led to different interpretations, and the controversies are compounded by the fact that two of the key protagonists in the field have the same name (Bin Zhou). This review is very timely in bringing together the recent advances in our understanding of coronary vessel development in a thorough and cohesive way [10].

Coronary artery disease (CAD) is the single largest cause of mortality worldwide, directly causing $12.8 \%$ of all deaths [11]. The most serious and acute manifestation of CAD is acute myocardial infarction (MI), which is characterized by myocardial damage caused by prolonged ischaemia. Therapies to salvage the injured myocardium and reduce cardiac damage are essential to improve outcomes for patients. Mesenchymal stem cells (MSCs) have been successfully used in pre-clinical studies to revascularise the ischaemic adult heart. These cells have immune privilege, as well as the potential to differentiate into different cell types. They also release paracrine factors to promote angiogenesis and modulate the immune response. These advantages coupled to their ability to activate endogenous cardiac cells mean that MSCs have quickly transferred to being used in clinical trials to promote heart repair following myocardial infarction (MI). The current take home message is that MSCs have great potential to promote heart repair following MI, but clinical trials to date suggest they provide at best only modest benefit in improving cardiac function. So the challenge now is to build on our understanding of the pro-angiogenic and pro-reparative mechanisms of MSCs in order to increase their therapeutic impact. In this issue Qingbo Xu

This article is protected by copyright. All rights reserved. 
and colleagues [3] summarise current progress in understanding the mechanisms involved in MSC-based therapy. One such potential mechanism is that revascularisation is promoted by extracellular vesicles released by MSCs, which contain the key proteins and nucleic acids to drive neovascularisation. It is even possible that future MSC based therapies may be replaced by these cell free mechanisms.

Finally, in our consideration of neovascularisation of the ischaemic heart, Costanza Emanueli and colleagues review an explosion of new insights into the roles of miRNAs, which are small non-coding RNAs that regulate protein and gene expression [8]. There is also growing interest in circulating extracellular vesicles that contain miRNAs within their cargo, and how these vesicles are released into the circulation and taken up by recipient cells to regulate target gene expression. This recently discovered mechanism of cell-cell communication in the heart following injury is currently a focus of many detailed investigations [7]. Of particular note is that the extracellular vesicles and their MiRNA contents are very stable giving them great potential for future off-the-shelf therapies to promote beneficial outcomes such as angiogenesis of the heart in acute ischaemia. For now, we are only just beginning to understand the complex regulatory roles of MiRNAs.

The acutely ischaemic heart is also a critical site where immune cells contribute to heart repair. The severity of post-infarction remodelling is dependent not only on the size of the infarct, but also on the qualitative characteristics of the reparative response. In their review Chen and Frangogiannis [2] elegantly explain how repair of the infarcted myocardium is dependent on an integrated immune response. Signals from hypoxic and dying cardiomyocytes trigger rapid recruitment of inflammatory immune cells to the ischaemic tissue. This is followed by dampening of the pro-inflammatory signals and a transition to reparative immune cells, particularly macrophages that promote neovascularisation and activation of fibroblasts required for formation of a collagen-based scar. However, the process is very complex and $\mathrm{Ml}$ patients are very heterogeneous so the challenge remains 
to convert our growing understanding of the immune response in the healing heart to successful therapeutic interventions to improve patient outcomes following MI [9].

Over the last 15 years, clinical therapy for ST elevation myocardial infarction (STEMI) has progressed significantly, with the development of primary percutaneous coronary intervention (PPCI), whereby the blocked coronary vessel is re-opened to re-perfuse the heart. However, there is growing recognition of problems due to occlusion of the cardiac microvessels and consequent loss of microvascular perfusion in these patients. Microvascular obstruction (MVO) can be observed in up to half of patients undergoing PPCI, depending on the cardiac magnetic resonance imaging (MRI) protocol used [13]. Coronary MVO results from the interplay between multiple factors, including endothelial dysfunction, inflammation, embolization of thrombus and plaque debris, and myocardial oedema [6]. MVO is associated with infarct expansion, adverse cardiac remodelling, and worse clinical outcomes, irrespective of infarct size (Figure 1)[12,14]. Several clinical trials have investigated multiple strategies to minimize coronary MVO, but so far no treatment has proven to successfully manage it. The in-depth review by Amedeo Chiribiri and colleagues [4] explains the limitations of diagnosing coronary microvascular dysfunction by conventional methods such as angiography and then describes invasive as well as non-invasive methods for its diagnosis. While the use of a combined pressure/temperature wire under hyperemia in the clinic is gaining increasing attention in order to assess the function of the coronary microcirculation, either through measuring coronary flow reserve or by using the index of microvascular resistance (IMR), non-invasive imaging by either cardiac MRI or Positron Emission Tomography (PET) can be used to quantify absolute myocardial blood flow, and enable a direct and accurate assessment of coronary microvascular function. The authors also provide a very detailed clinical classification of coronary microvascular dysfunction, which emphasises the relevance of the coronary microcirculation in non-obstructive CAD, cardiomyopathies and reperfusion injury.

This article is protected by copyright. All rights reserved. 
In his primary research article Paolo Camici and colleagues [5] investigate the effect of 8 different antihypertensive drugs on the coronary microcirculation in spontaneous hypertensive rats. They found that anti-hypertensive treatment on coronary microvascular dysfunction (CMD) is not only dependent on blood pressure reduction, but that compounds with comparable anti-hypertensive efficacy may exert different effects on hyperemic coronary blood flow and induce different degrees of reverse arteriolar remodelling. All of the tested antihypertensive drugs lead to a reduction in medial thickness or interstitial fibrosis. However, only perindopril and candesartan significantly improved hyperemic coronary flow. The observed lack of correlation between medial thickness and coronary blood flow illustrates that endothelial function and arteriolar remodelling can be targeted separately by different drugs, and this finding should be considered in patients with dysfunction of the coronary microvasculature. As highlighted in this meeting, CMD is gaining recognition as an important cause of myocardial ischaemia with critical implications for treatment options and patient prognosis [1].

In conclusion, the articles in this issue represent a very timely consideration of recent advances in understanding coronary vessel development and therapies for revascularisation of the ischaemic heart. In patients with $C A D$, we are developing a growing appreciation of the critical importance of MVO and how it contributes to cardiac pathology. Consideration of how imaging technologies can be used to efficiently visualise MVO in patients has opened up opportunities to better understand how MVO impacts on patient prognosis and to appropriately prioritise patients for further treatment. Meanwhile an urgent goal is to better understand the pathophysiology of MVO so we can meet the clinical challenge of improving microvascular reflow in affected heart patients.

This article is protected by copyright. All rights reserved. 


\section{Acknowledgements}

The authors are grateful for the generous sponsorship of the 66th annual meeting of the

British Microcirculation Society from Microcirculation, British Heart Foundation, Newcastle

University and Nectar (Newcastle Cardiovascular Trials and Research).

\section{Figure legends}

Figure 1. Prognostic relevance of Coronary MVO. Kaplan-Meier survival curve showing that patients with coronary MVO have a higher cumulative 2-year event rate than those without MVO, (events include cardiovascular death, reinfarction, congestive heart failure, or stroke). Figure from: Wu, KC et al [14]

References

1. Camici PG, d'Amati G, Rimoldi O. Coronary microvascular dysfunction: mechanisms and functional assessment. Nature reviews Cardiology 12: 48-62, 2015.

2. Chen B, Frangogiannis NG. Immune cells in repair of the infarcted myocardium. Microcirculation, 2016. UMIC-2016-0058.R1

3. Gu W, Hong X, Potter C, Qu A, Xu Q. Mesenchymal Stem Cells and Vascular Regeneration. Microcirculation, 2016. UMIC-2016-0051.R1

4. Joy S. Shome DP, Sven Plein, Amedeo Chiribiri. Current Perspectives in Coronary Microvascular Dysfunction. Microcirculation Manuscript ID UMIC-2016-0092.

5. Mancini M, Scavone A, Sartorio CL, Baccaro R, Kleinert C, Pernazza A, Buia V, Leopizzi M, D'Amati G, Camici PG. Effect of different drug classes on reverse remodeling of intramural coronary arterioles in the spontaneously hypertensive rat. Microcirculation, 2016. UMIC-20160022.R1

6. Roe MT, Ohman EM, Maas AC, Christenson RH, Mahaffey KW, Granger CB, Harrington RA, Califf RM, Krucoff MW. Shifting the open-artery hypothesis downstream: the quest for optimal reperfusion. Journal of the American College of Cardiology 37: 9-18, 2001.

7. Sahoo S, Losordo DW. Exosomes and cardiac repair after myocardial infarction. Circulation research 114: 333-344, 2014.

8. Sasso L, Hosamuddin H, Emanueli C. Extracellular Vesicles at the Cross-line between Basic Science and Clinical Needs. Microcirculation Manuscript ID UMIC-2016-0075

This article is protected by copyright. All rights reserved. 
9. Saxena A, Russo I, Frangogiannis NG. Inflammation as a therapeutic target in myocardial infarction: learning from past failures to meet future challenges. Translational research : the journal of laboratory and clinical medicine 167: 152-166, 2016.

10. Smart N. Prospects for Improving Neovascularisation of the Ischaemic Heart: Lessons from Development. Microcirculation Manuscript ID UMIC-2016-0095.

11. Steg PG, James SK, Atar D, Badano LP, Blomstrom-Lundqvist C, Borger MA, Di Mario C, Dickstein K, Ducrocq G, Fernandez-Aviles F, Gershlick AH, Giannuzzi P, Halvorsen S, Huber K, Juni $P$, Kastrati A, Knuuti J, Lenzen MJ, Mahaffey KW, Valgimigli M, van 't Hof A, Widimsky P, Zahger D. ESC Guidelines for the management of acute myocardial infarction in patients presenting with STsegment elevation. European heart journal 33: 2569-2619, 2012.

12. van Kranenburg $M$, Magro $M$, Thiele $H$, de Waha $S$, Eitel $I$, Cochet $A$, Cottin $Y$, Atar $D$, Buser $P$, Wu E, Lee D, Bodi V, Klug G, Metzler B, Delewi R, Bernhardt P, Rottbauer W, Boersma E, Zijlstra F, van Geuns RJ. Prognostic value of microvascular obstruction and infarct size, as measured by CMR in STEMI patients. JACC Cardiovascular imaging 7: 930-939, 2014.

13. Wu KC. CMR of microvascular obstruction and hemorrhage in myocardial infarction. Journal of cardiovascular magnetic resonance : official journal of the Society for Cardiovascular Magnetic Resonance 14: 68, 2012.

14. Wu KC, Zerhouni EA, Judd RM, Lugo-Olivieri CH, Barouch LA, Schulman SP, Blumenthal RS, Lima JA. Prognostic significance of microvascular obstruction by magnetic resonance imaging in patients with acute myocardial infarction. Circulation 97: 765-772, 1998.

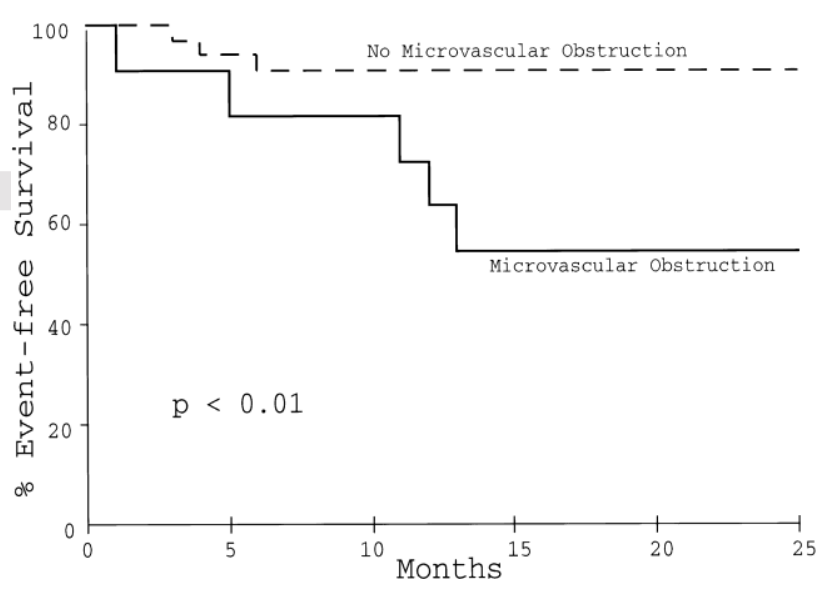

This article is protected by copyright. All rights reserved. 